\title{
Effect of Topdressed Controlled-release Fertilizer Rates on Nursery Crop Quality and Growth and Growing Substrate Nutrient Status in the Niagara Region, Ontario, Canada
}

\author{
Mary Jane Clark \\ Vineland Research and Innovation Centre, 4890 Victoria Avenue North, Box \\ 4000, Vineland Station, Ontario, LOR 2E0, Canada
}

\begin{abstract}
Youbin Zheng ${ }^{1}$
Vineland Research and Innovation Centre, 4890 Victoria Avenue North, Box 4000, Vineland Station, Ontario, LOR 2E0, Canada; and School of Environmental Sciences, University of Guelph, 50 Stone Road East, Guelph, Ontario, N1G 2W1, Canada
\end{abstract}

Additional index words. nitrogen, mineral nutrition, spirea, weigela, production timing

\begin{abstract}
The objectives of the current study were to 1) determine the best topdressed controlled-release fertilizer (CRF) application rates for quality and growth of two nursery crops under temperate climate outdoor nursery production conditions in the Niagara region, Ontario, Canada, and 2) evaluate the nutrient status of the growing substrate following topdressing of two CRF types during the growing season. Falltransplanted Goldmound spirea (Spiraea $\times$ bumalda 'Goldmound') and Wine \& Roses ${ }^{\circledR}$ weigela [Weigela florida (Bunge) A. DC. 'Alexandra'] were grown in 2-gal $(7.56 \mathrm{~L})$ containers and topdressed on 7 May 2015 with Osmocote Plus 15N-3.9P-9.9K, 5-6 month CRF or Plantacote 14N-3.9P-12.5K, 6 month Homogeneous NPK with Micros. CRF was applied at rates of $1.5,3.0,4.5,6.0,7.5$, and $9.0 \mathrm{~g}$ nitrogen $(\mathrm{N}) /$ pot for both species. The best plants at the end of the growing season (i.e., 23 Sept. 2015) were spirea at 3.0-4.5 and 3.0-6.0 $\mathrm{g} \mathrm{N} /$ pot, and weigela at 3.0-4.5 and $6.0 \mathrm{~g} \mathrm{~N} /$ pot, with Osmocote and Plantacote, respectively. At CRF rates above these rates, the majority of plants showed no increase in growth or quality attributes. All weigela plants, despite CRF application rate, showed K deficiency symptoms during the study. Using marketable-size criteria and plant growth data over time, estimates of production timing are presented for falltransplanted, spring-topdressed weigela and spirea. These estimates may assist growers in choosing CRF application rates to meet time-sensitive production goals. Early in the growing season, $\mathrm{NO}_{3}-\mathrm{N}$ and $\mathrm{P}$ concentrations in the growing substrate were highest at CRF rates $\geq 4.5$ and $\geq 6.0 \mathrm{~g} \mathrm{~N} /$ pot, respectively, and $P$ continued to be high in August and September at $9.0 \mathrm{~g} \mathrm{~N} /$ pot. $\mathrm{NH}_{3}-\mathrm{N}$ and $\mathrm{K}$ concentrations at all $\mathrm{CRF}$ application rates were greater early in the growing season and decreased over time. At high CRF rates toward the end of the growing season, concentrations of $\mathrm{NO}_{3}-\mathrm{N}, \mathrm{NH}_{3}-\mathrm{N}$, and $\mathrm{P}$ once again increased. Considering crop-specific CRF application rates and understanding changes in growing substrate nutrient status during the growing season may help nursery growers prevent negative environmental impacts from over-fertilizing.
\end{abstract}

Early-season leaching of nutrients is a concern during container nursery crop production in many countries including the United States, Canada, Italy, and Spain

Received for publication 26 Aug. 2016. Accepted for publication 15 Nov. 2016.

This work was financially supported by Agriculture and Agri-Food Canada through the Canadian Ornamental Horticulture Alliance (COHA), Landscape Ontario, J.C. Bakker \& Sons Wholesale Nurseries, ICL Specialty Fertilizers and Kam's Growers Supply Inc.

We thank Hillary MacDougall, Sarah Hall, and Micah Diller Harder for their technical assistance during the experiment.

${ }^{1}$ Corresponding author. E-mail: yzheng@uoguelph.ca.
Narvaez et al., 2012; Newman et al., 2006). Warm outdoor temperatures and regular rain and irrigation events during early-season outdoor container nursery crop establishment (i.e., in May and June) provide ideal conditions for nutrient release from CRFs, which elevates nutrient levels in the growing substrate. At this time, when plant root systems are small and unable to use all of the released nutrients, excess nutrients are leached, with potentially negative environmental impacts; this loss also represents a production cost for nursery growers (Majsztrik et al., 2011; Yeager et al., 1993). CRF application method (i.e., topdressing vs. incorporating), CRF type (i.e., Polyon, Nutricote, Osmocote, etc.) as well as environmental conditions (i.e., temperature and moisture) influence nutrient status and consequently can influence nutrient leaching over time (Alam et al., 2009; Birrenkott et al., 2005; Cabrera, 1997; Lunt and Oertli, 1962; Ruter, 1992).

The nutrient status of a growing substrate is greatly influenced by the nutrient release characteristics of the applied fertilizer. Individual CRF types are characterized by their release duration, based on the prill coating specifications, which are determined in controlled laboratory conditions at a constant temperature and moisture. However, during outdoor nursery production, CRF release duration is also influenced by fluctuating outdoor temperatures, and variable precipitation levels; therefore, the actual nutrient release duration may vary considerably from the laboratory-determined value (Agro and Zheng, 2014; Clark and Zheng, 2015). For example, CRF release durations of 5-6, 6-7, 8-9, and 10-12 months are commonly used in Ontario nursery production; however, the observed duration of nutrient release has been shorter than expected for CRFs (Agro and Zheng, 2014; Clark and Zheng, 2015; Husby, 2000). In addition, despite similarly described longevities, different CRF types have dissimilar nutrient release patterns, even under greenhouse conditions (Cabrera, 1997). Besides CRF nutrient release characteristics, nutrient status is also influenced by CRF application rate. In Ontario, many nurseries transplant in the spring, and fertilization of newly planted container-grown nursery crops commonly occurs at generalized rates for low-, medium-, or high-feeding crops, or at one rate for the entire nursery. Previous temperate climate research has indicated the optimum CRF rates and ranges for springplanted nursery crops are species specific with excess incorporated CRF causing a high growing substrate nutrient status and nutrient loss (Agro, 2014; Clark and Zheng, 2015). For some species, or at some Ontario nurseries, fall planting is preferred and CRF is often applied to the surface of the growing substrate (i.e., topdressed) the following spring, instead of being incorporated at planting in the fall. However, for topdressed CRF applications, optimum species-specific CRF rates are not known for most nursery crops. Therefore, the specific objectives of the current study were to 1) determine the 
best topdressed CRF application rates for quality and growth of two nursery crops under temperate climate outdoor nursery production conditions in the Niagara region of Ontario, Canada, and 2) evaluate the nutrient status of the growing substrate following topdressing of two commonly used CRF types during the growing season.

\section{Materials and Methods}

Plant material and fertilization. Goldmound spirea (Spiraea ×bumalda 'Goldmound') and Wine \& Roses ${ }^{\circledR}$ weigela $(W$. florida 'Alexandra'), two commonly grown, economically important nursery crops were transplanted Fall 2014 into two-gallon (i.e., 2-gal, $7.56 \mathrm{~L}$ ) containers filled with $\approx 7.56 \mathrm{~L}$ of a proprietary custom-blended compostand bark-based growing substrate (Fafard \& Freres Ltee, Saint-Bonaventure, QC). After transplanting, plants were fertilized twice with a $20 \mathrm{~N}-8.7 \mathrm{P}-16.6 \mathrm{~K}$ water-soluble fertilizer (Plant Products, Ancaster, ON), based on grower specifications. Spirea plants were over-wintered under white thermoblankets, and weigela plants were over-wintered in hoop houses under one layer of 55\% opacity 3-mil poly, both with pot-tight spacing at a commercial nursery in St. Catharines, $\mathrm{ON}$ (lat. $43.18^{\circ} \mathrm{N}$, long. $79.29^{\circ} \mathrm{W}$ ). The thermoblankets and poly were removed on 1 and 12 Apr. 2015, respectively, and after 6-8 weeks of growth (i.e., June 2015), plants were spaced $\approx 6 \mathrm{~cm}$ apart.

During the 2015 growing season (Apr. to Oct. 2015), plants were grown outdoors on black weed-barrier fabric and weeded monthly. Following fertilization on 7 May 2015, spirea were not pruned and clippings from all weigela pruning events (i.e., 10 June, 21 and 30 July, and 21 Aug. 2015) were collected, dried in an oven at $70{ }^{\circ} \mathrm{C}$ and weighed, to contribute to the total shoot dry weight.

On 7 May 2015, Osmocote Plus 15N3.9P-9.9K, 5-6 month (ICL Specialty Fertilizers, Dublin, $\mathrm{OH}$ ) and Plantacote $14 \mathrm{~N}-$ 3.9P-12.5K, 6-month Homogeneous NPK with Micros (Kam's Growers Supply, Inc., Guelph, ON), were each topdressed by hand to containers to deliver rates of $1.5,3.0,4.5$, $6.0,7.5$, and $9.0 \mathrm{~g} \mathrm{~N} /$ pot. Fertilizer rates were selected based on general nursery crop recommendations made by fertilizer suppliers, nursery grower suggestions, and previous studies (Agro, 2014; Agro and Zheng, 2014; Alam et al., 2009; Clark and Zheng, 2015). The mean initial growing substrate $\mathrm{pH}$ values were 7.32 and 7.39, and the electrical conductivity (EC) values were 0.8 and 0.4 $\mathrm{mS} \cdot \mathrm{cm}^{-1}$, for spirea and weigela, respectively $(n=12)$, on 7 May 2015, evaluated using the pour-through method (Wright, 1986). Before fertilizer application, growing substrate plant-available nutrient status for spirea and weigela, respectively, were as follows: 6.0 and $4.0 \mathrm{mg} \cdot \mathrm{kg}^{-1}$ nitrate $\left(\mathrm{NO}_{3}{ }^{-}\right)-\mathrm{N}, 5.5$ and $4.3 \mathrm{mg} \cdot \mathrm{kg}^{-1}$ ammonium $\left(\mathrm{NH}_{4}^{+}\right)-\mathrm{N}, 6.5$ and $5.2 \mathrm{mg} \cdot \mathrm{kg}^{-1}$ phosphorus (P), 112.6 and $114.6 \mathrm{mg} \cdot \mathrm{kg}^{-1}$ potassium $(\mathrm{K}), 13.3$ and
$10.5 \mathrm{mg} \cdot \mathrm{kg}^{-1}$ magnesium $(\mathrm{Mg}), 54.3$ and 46.7 and $\mathrm{mg} \cdot \mathrm{kg}^{-1}$ calcium (Ca), 105.8 and $80.3 \mathrm{mg} \cdot \mathrm{kg}^{-1}$ sulfate $\left(\mathrm{SO}_{4}\right), 50.0$ and $29.5 \mathrm{mg} \cdot \mathrm{kg}^{-1}$ sodium $(\mathrm{Na})$, and 33.0 and $28.0 \mathrm{mg} \cdot \mathrm{kg}^{-1}$ chloride $(\mathrm{Cl})$, as analyzed using the saturated paste extraction method (SGS Agri-Food Laboratories, Guelph, ON).

Plants were irrigated with local municipal water ( $\mathrm{pH} 7.58-7.92$; EC $\left.0.30-0.34 \mathrm{mS} \cdot \mathrm{cm}^{-1}\right)$ using overhead sprinklers, as per standard production practices based on evapotranspiration calculations (Argus Control Systems Ltd, Surrey, BC, Canada). Local municipal water was used to irrigate all plants during the study, and the irrigation water $\mathrm{pH}$ and $\mathrm{EC}$ ranged from 7.58 to 7.92 and 0.30 to 0.34 $\mathrm{mS} \cdot \mathrm{cm}^{-1}$, respectively, during the 2015 growing season. Total monthly precipitation for the region was $45.7,128.7,28.5,40.3,79.7$, $59.4,22.0$, and $29.1 \mathrm{~mm}$ in May, June, July, Aug., Sept., Oct., Nov., and Dec. 2015, respectively, as well as $23.4,69.2,81.8$, 26.1, and $15.5 \mathrm{~mm}$ for Jan., Feb., Mar., Apr., and May 2016, respectively (Environment Canada, 2016). Monthly mean minimum and maximum air temperatures were 8.5 to $19.3,13.1$ to $20.0,17.9$ to $25.7,17.6$ to $25.0,16.8$ to $23.6,9.0$ to $15.0,5.2$ to 11.7 , and 3.3 to $8.2^{\circ} \mathrm{C}$ in May, June, July, Aug., Sept., Oct., Nov., and Dec. 2015, respectively, as well as -4.2 to $1.6,-4.8$ to $3.1,-0.4$ to $7.8,0.7$ to 9.4 , and 8.6 to $14.1^{\circ} \mathrm{C}$ for Jan., Feb., Mar., Apr., and May 2016, respectively (Environment Canada, 2016). All plants were overwintered between 5 Nov. 2015 and 1 Apr. 2016 in hoop houses under one layer of $55 \%$ opacity 3-mil poly.

Experimental design. Treatments (CRF type $\times$ rate) were arranged in a completely randomized design within species with 10 single plant replicates per species. Each species group was bordered with extra plants of the same species to reduce perimeter effects. Plants were rerandomized monthly to reduce location effects.

Measurements. Plant growth was evaluated monthly from 7 May to 10 Oct. 2015 by measuring plant height and canopy width, in two perpendicular directions, for five plants per species per CRF type and rate treatment. Aboveground plant growth index was calculated as [(height $\times$ width $_{1} \times$ width $\left.\left._{2}\right) / 300\right]$, as outlined by Ruter (1992). Chlorophyll content was measured using a CCM-300 Chlorophyll Content Meter (Opti-Sciences, Inc., Hudson, NH). Growing substrate $\mathrm{pH}$ and EC were measured for five plants per species per CRF type and rate treatment weekly from 7 May to 3 June 2015 and biweekly thereafter until 12 Oct. 2015 using the pour-through method (Wright, 1986). To determine growing substrate nutrient concentration, pourthrough solution from spirea with Osmocote CRF was analyzed monthly for $\mathrm{NO}_{3}-\mathrm{N}, \mathrm{NH}_{3}-$ $\mathrm{N}$, P, and $\mathrm{K}$ using a Varian Vista Pro ICPOES with axially viewed plasma (Varian Inc., Australia; SGS Agri-Food Laboratories, Guelph, ON). Growing substrate volumetric water content and temperature were measured at 10 min intervals by an Em50 datalogger equipped with 5TM sensors (Hoskin
Scientific, Burlington, ON) from 10 June 2015 to 20 May 2016 by inserting one 5TM sensor into the growing substrate for each of four spirea plants. The four spirea plants measured with the dataloggers had one of the following CRF applications: Osmocote or Plantacote applied at 4.5 or $6.0 \mathrm{~g} \mathrm{~N} /$ pot.

Nursery growers, industry professionals, and researchers formed the evaluation team who visually evaluated plants on 1 and 23 Sept. 2015 to determine which CRF rates produced the best plants for each species and CRF type combination, according to industry standards. In Oct. 2015, the marketable size category for all plants was determined based on plant diameters of 25,30 , or $40 \mathrm{~cm}$. Six of 10 plants per species, for each CRF type and rate, were evaluated the following spring (i.e., on 18 May 2016), for winter injury based on overall appearance, plant quality, and plant health characteristics.

Leaf area was measured in Oct. 2015 for four of 10 plants per species per CRF type and rate using a leaf area meter (LI-3100; LICOR, Lincoln, NE). Root growth evaluations visually determined the total coverage of roots around the perimeter of the containerized root zone. Final shoot dry weight was evaluated in Oct. 2015 for four plants per species per CRF rate by weighing all aboveground tissue, after drying in a forced air oven at $70{ }^{\circ} \mathrm{C}$ for $5 \mathrm{~d}$, or until a constant weight was achieved. Total shoot dry weight was calculated from the sum of final shoot dry weight and dry weights of all clippings from pruning events during the growing season.

Statistical analysis. Data were subject to a one-way analysis of variance (ANOVA) for chlorophyll content and root growth, with differences among means determined according to Tukey's multiple comparison test. A two-way repeated measures ANOVA with a Bonferroni posttest was used to evaluate differences among CRF rate treatments and time points for growth index and substrate nutrient concentration, substrate EC and $\mathrm{pH}$, per species and CRF type. Regression analyses with extra sum-of-squares $F$ tests were used to evaluate root zone nutrient status, EC and $\mathrm{pH}$, growth index, plant diameter over time, shoot dry weight, leaf area, and chlorophyll content among CRF rates to estimate regression parameters for the best-fit regression model (linear, quadratic, or cubic). Pearson correlation coefficients were calculated to compare substrate $\mathrm{EC}$ and $\mathrm{pH}$ with nutrient concentrations for each time point at each $\mathrm{CRF}$ rate. All data sets were analyzed using GraphPad Prism, version 5.03 software (GraphPad Software Inc., La Jolla, CA) using a significance level of $P<0.05$.

\section{Results}

Topdressed CRF rate influenced the growth and quality of 2-gal spirea and weigela during production under commercial conditions in the first growing season after application. 
Plant quality. On 1 Sept. 2015, the fertilizer rates which produced the best quality plants were selected by the evaluation team to be $6.0 \mathrm{~g} \mathrm{~N} /$ pot for spirea and weigela with Plantacote and $4.5 \mathrm{~g} \mathrm{~N} /$ pot for spirea with Osmocote, while the best fertilizer range was identified as 3.0-6.0 $\mathrm{g} \mathrm{N} /$ pot for weigela with Osmocote. At the end of the growing season (23 Sept. 2015), the best fertilizer rate continued to be $6.0 \mathrm{~g} \mathrm{~N} /$ pot for weigela with Plantacote, while the best fertilizer ranges were 3.0-4.5 g N/pot for spirea and weigela with Osmocote and 3.0-6.0 g N/pot for spirea with Plantacote.

Chlorophyll content. Mid-canopy leaf chlorophyll content, measured monthly from June to Oct. 2015, generally increased with increasing CRF rate for both spirea and weigela grown with both Osmocote and Plantacote for the majority of dates, particularly at late-season time points (Fig. 1). The chlorophyll content of spirea grown with Osmocote and weigela grown with Plantacote was greater at 6.0, 7.5, and $9.0 \mathrm{~g} \mathrm{~N} /$ pot than at lower CRF rates on 12 Oct. 2015. For spirea grown with Plantacote, leaf chlorophyll content was greatest at $9.0 \mathrm{~g} \mathrm{~N} /$ pot but did not differ at rates from 4.0 to $7.5 \mathrm{~g} \mathrm{~N} /$ pot. The chlorophyll content of weigela grown with Osmocote was greatest at high CRF rates and did not differ among CRF rates $>6.0 \mathrm{~g} \mathrm{~N} /$ pot.

Despite the natural yellow leaf color of Goldmound spirea, when grown at $1.5 \mathrm{~g} \mathrm{~N} /$ pot with both CRF types, very light yellow young leaves were observed at the end of the growing season, symptomatic of $\mathrm{N}$ deficiency. Early in the study during June and July, weigela at all CRF rates and types had yellow and brown margins on mature leaves, symptomatic of $\mathrm{K}$ deficiency, becoming more severe with time.

When evaluated for winter injury on 18 May 2016, none of the spirea or weigela plants showed any winter injury damage symptoms, and all were marketable.

Plant growth. The influence of CRF rate on growth index was observed less than 1 month after topdress application (i.e., on 3 June 2015) for spirea grown with Osmocote and weigela grown with Plantacote, and for all treatments by 1 July 2015 (data not shown). Both shoot dry weight and leaf area measured in Oct. 2015 showed a quadratic response for spirea and a linear response for weigela with both CRF types when CRF rates were increased (Fig. 2). From the regression relationship, the greatest spirea shoot dry weight and leaf area were calculated to occur with application of 6.43 and $7.12 \mathrm{~g} \mathrm{~N} / \mathrm{pot}$ Osmocote, and 9.14 and $8.51 \mathrm{~g} \mathrm{~N} /$ pot Plantacote, respectively.

Root growth evaluations completed on 14 Oct. 2015 determined that visually evaluated root coverage around the perimeter of the containerized root zone was greater for spirea grown with Osmocote at 3.0, 4.5, and $6.0 \mathrm{~g} \mathrm{~N} /$ pot than at $1.5 \mathrm{~g} \mathrm{~N} /$ pot; however, when spirea was grown with Plantacote and weigela with both CRF types, no differences in root growth were observed irrespective of the CRF rate used (data not shown).

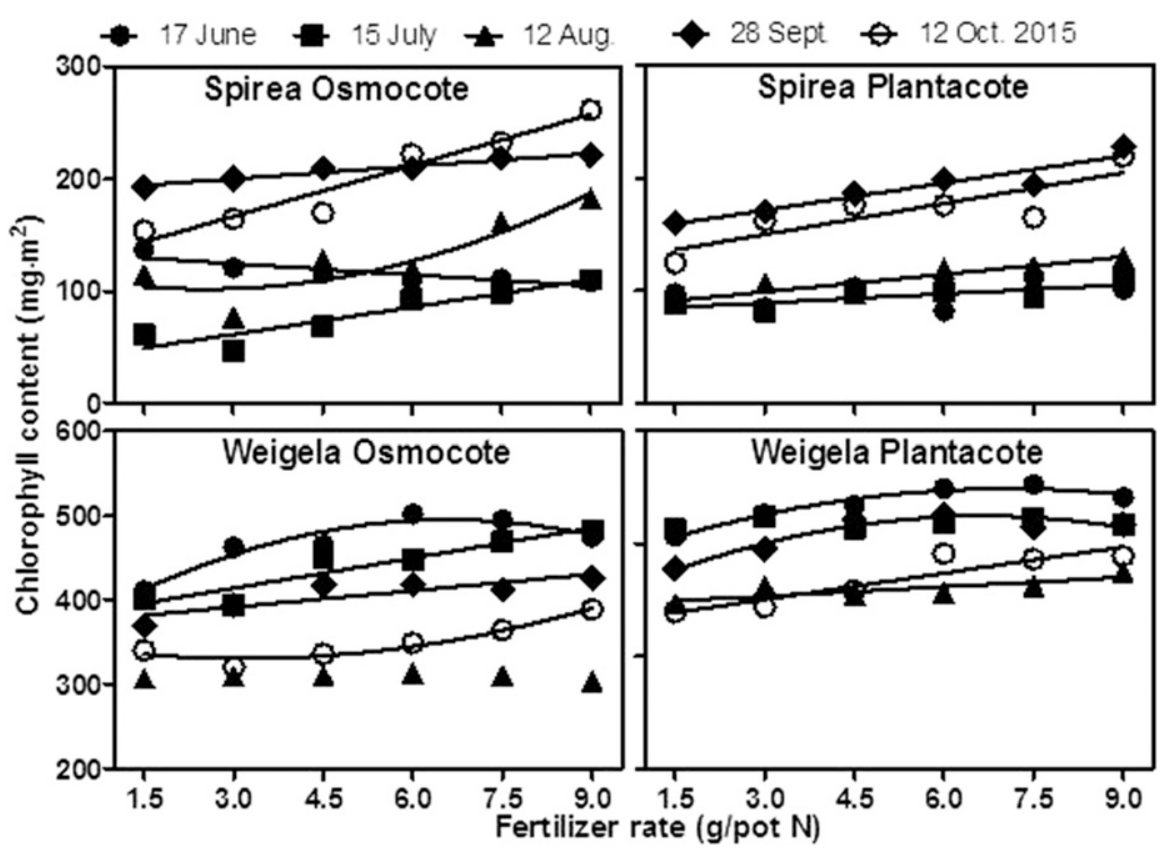

Fig. 1. Leaf chlorophyll content for spirea and weigela topdressed on 7 May 2015 with Osmocote Plus $15 \mathrm{~N}-3.9 \mathrm{P}-9.9 \mathrm{~K}, 5-6$ month or Plantacote 14N-3.9P-12.5K, 6 month Homogeneous NPK with Micros controlled-release fertilizer, applied at six rates. Data are means of five replicates. Where effect of fertilizer rate was significant $(P<0.05)$, lines indicate the calculated regression, otherwise no lines are shown.

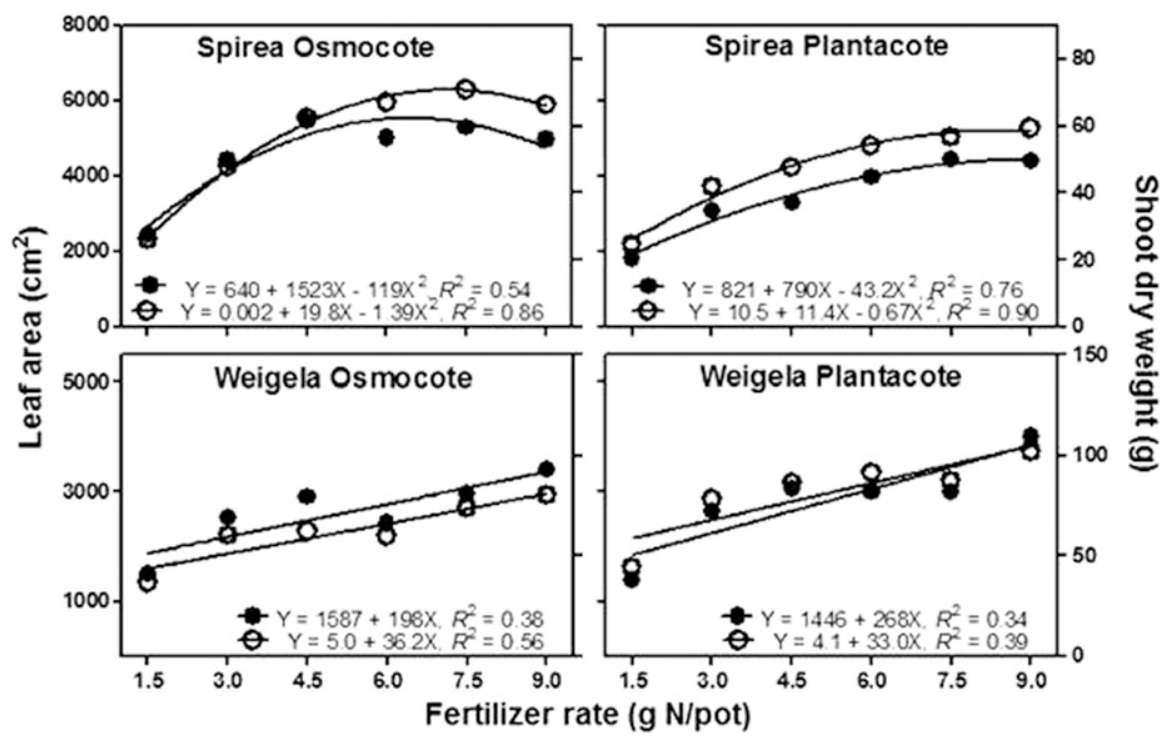

Fig. 2. Leaf area $(\bullet)$ and shoot dry weight per plant $(\bigcirc)$ in Oct. 2015 for spirea and weigela grown with Osmocote Plus 15N-3.9P-9.9K, 5-6 month or Plantacote 14N-3.9P-12.5K, 6 month Homogeneous NPK with Micros controlled-release fertilizer, topdressed at six rates on 7 May 2015. Data are means of four replicates. Where effect of fertilizer rate was significant $(P<0.05)$, lines indicate the calculated regression.

Production timing. Nursery shrub production timing aims to satisfy industry demand and buyer preferences of plant size (diameter), i.e., 25,30 , and $40 \mathrm{~cm}$. All spirea and weigela grown with both CRF types at $1.5 \mathrm{~g} \mathrm{~N} /$ pot were graded as $25 \mathrm{~cm}$. For spirea at CRF rates $\geq 3.0 \mathrm{~g} \mathrm{~N} /$ pot, $95 \%$ and $85 \%$ of plants were graded as $40 \mathrm{~cm}$ when grown with Osmocote and Plantacote, respectively. For weigela at CRF rates $\geq 3.0 \mathrm{~g} \mathrm{~N} /$ pot, $45 \%$ and $40 \%$ of plants were graded as 40 and 30 cm with Osmocote, respectively, while with Plantacote $25 \%$ and $55 \%$ of plants were graded as 40 and $30 \mathrm{~cm}$, respectively. The remainder of weigela plants with both CRF types was graded as $25 \mathrm{~cm}$.

From the regression relationship of measured plant diameter and CRF rate (Table 1; Fig. 3), spirea plants fertilized at $7.5 \mathrm{~g} \mathrm{~N} /$ pot reached the $40 \mathrm{~cm}$ marketable size the fastest among all CRF rates, i.e., a diameter of $40 \mathrm{~cm}$ was reached on Day 66 (12 July) and Day 97 
Table 1. Predicted number of days for Goldmound spirea and Wine \& Roses ${ }^{\circledR}$ weigela to reach marketable diameters of 25,30 , and $40 \mathrm{~cm}$, following topdress application of controlled-release fertilizer (CRF) at six rates.

\begin{tabular}{|c|c|c|c|c|c|c|c|c|}
\hline \multirow{2}{*}{$\begin{array}{l}\text { CRF rate } \\
\text { (g N/pot) }\end{array}$} & \multicolumn{4}{|c|}{ Osmocote $^{\mathrm{z}}$} & \multicolumn{4}{|c|}{ Plantacote $^{\mathrm{y}}$} \\
\hline & \multicolumn{3}{|c|}{ Days to reach marketable diam } & Regression equation & \multicolumn{3}{|c|}{ Days to reach marketable diam } & Regression equation \\
\hline \multicolumn{9}{|l|}{ Spirea } \\
\hline 3.0 & 35 & 49 & 82 & $Y=9.0+0.51 X-0.002 X^{2}$ & 51 & 71 & 133 & $Y=9.0+0.37 X-0.001 X^{2}$ \\
\hline 4.5 & 33 & 45 & 72 & $Y=7.8+0.58 X-0.002 X^{2}$ & 44 & 63 & 110 & $Y=10.0+0.38 X-0.001 X^{2}$ \\
\hline 6.0 & 33 & 44 & 69 & $Y=7.0+0.61 X-0.002 X^{2}$ & 58 & 78 & 130 & $Y=7.5+0.34 X-0.0007 X^{2}$ \\
\hline 7.5 & 31 & 41 & 66 & $Y=7.4+0.64 X-0.002 X^{2}$ & 43 & 58 & 97 & $Y=7.4+0.47 X-0.001 X^{2}$ \\
\hline 1.5 & 42 & 59 & 109 & $Y=8.2+0.47 X-0.002 X^{2}$ & 61 & 89 & N/A & $Y=7.5+0.36 X-0.001 X^{2}$ \\
\hline 3.0 & 42 & 57 & 96 & $Y=8.7+0.44 X-0.001 X^{2}$ & 56 & 78 & N/A & $Y=7.7+0.37 X-0.001 X^{2}$ \\
\hline 4.5 & 37 & 49 & 82 & $Y=7.3+0.55 X-0.002 X^{2}$ & 64 & 86 & 130 & $Y=10.5+0.23 X$ \\
\hline 6.0 & 36 & 48 & 79 & $Y=7.6+0.54 X-0.002 X^{2}$ & 44 & 63 & 112 & $Y=9.7+0.39 X-0.001 X^{2}$ \\
\hline 7.5 & 33 & 44 & 70 & $Y=6.6+0.63 X-0.002 X^{2}$ & 51 & 72 & 143 & $Y=8.8+0.37 X-0.001 X^{2}$ \\
\hline 9.0 & 35 & 46 & 73 & $Y=6.2+0.61 X-0.002 X^{2}$ & 45 & 61 & 101 & $Y=8.4+0.42 X-0.001 X^{2}$ \\
\hline
\end{tabular}

${ }^{\mathrm{z}}$ Osmocote Plus 15N-3.9P-9.9K, 5-6 month CRF.

${ }^{\mathrm{y}}$ Plantacote $14 \mathrm{~N}-3.9 \mathrm{P}-12.5 \mathrm{~K}, 6$ month Homogeneous NPK with Micros CRF.

${ }^{x}$ Plants did not reach this diameter during the current study.

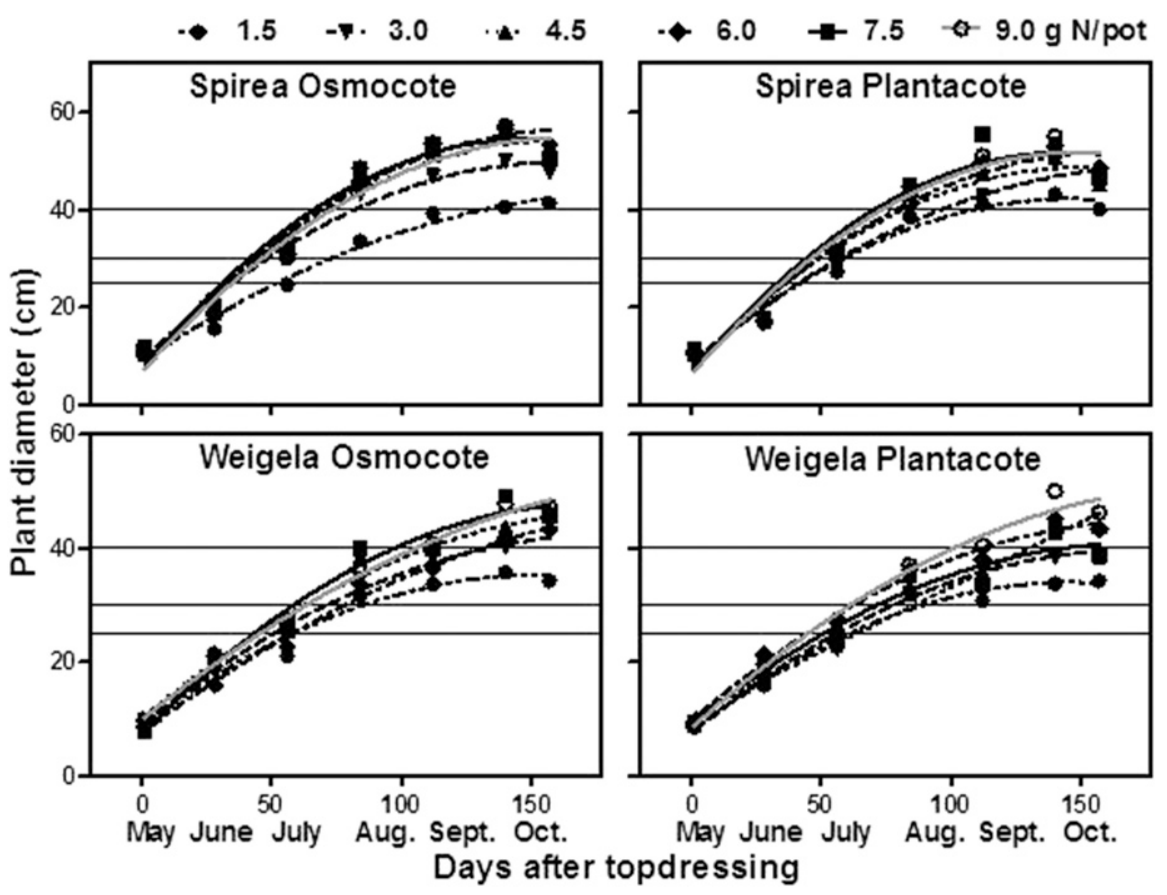

Fig. 3. Plant diameter for spirea and weigela topdressed on 7 May 2015 with Osmocote Plus $15 \mathrm{~N}-3.9 \mathrm{P}-$ 9.9K, 5-6 month or Plantacote 14N-3.9P-12.5K, 6 month Homogeneous NPK with Micros controlledrelease fertilizer, applied at six rates. Data are means of five replicates. Where effect of time was significant $(P<0.05)$, lines indicate the calculated regression, otherwise no lines are shown. Horizontal gridlines indicate marketable-size benchmarks (i.e., 25,30 , and $40 \mathrm{~cm}$ ).

(12 Aug.) for plants grown with Osmocote and Plantacote, respectively. For weigela, plants fertilized with Osmocote at $7.5 \mathrm{~g} \mathrm{~N} /$ pot and Plantacote at $9.0 \mathrm{~g} \mathrm{~N} /$ pot reached 40 cm by Day 70 (16 July) and Day 101 (16 Aug.), respectively. Compared with CRF application at $1.5 \mathrm{~g} \mathrm{~N} /$ pot, fertilization with Osmocote at $7.5 \mathrm{~g} \mathrm{~N} /$ pot has the potential to reduce the total production time needed to reach the $40-\mathrm{cm}$ marketable size by 66 or $38 \mathrm{~d}$ for spirea and weigela, respectively. When grown with Plantacote at $1.5 \mathrm{~g} \mathrm{~N} /$ pot, neither spirea nor weigela reached the required $40 \mathrm{~cm}$ diameter $157 \mathrm{~d}$ after CRF application. However, for plants grown with Plantacote at
$7.5 \mathrm{~g} \mathrm{~N} /$ pot, a 30-cm diameter was reached on Day 58 (4 July) for spirea (i.e., $27 \mathrm{~d}$ earlier than with $1.5 \mathrm{~g} \mathrm{~N} /$ pot); and for weigela grown with $9.0 \mathrm{~g} \mathrm{~N} /$ pot, $30-\mathrm{cm}$ diameter was reached on Day 61 (7 July) (i.e., 28 d earlier than with $1.5 \mathrm{~g} \mathrm{~N} /$ pot).

Root zone nutrient status. The nutrient status, EC and $\mathrm{pH}$ of the growing substrate varied over the growing season, for the representative treatment of Spirea with Osmocote, at different CRF application rates (Figs. 4-6).

Root zone $\mathrm{NO}_{3}-\mathrm{N}$ status for spirea grown with Osmocote changed over time for the majority of CRF rates. However, at $1.5 \mathrm{~g} \mathrm{~N} /$ pot, the $\mathrm{NO}_{3}-\mathrm{N}$ status did not vary significantly among all time points from May to Oct. 2015 (Fig. 4). At 3.0 g N/pot, the $\mathrm{NO}_{3}-\mathrm{N}$ status was significantly higher in May than Aug. 2015 (Fig. 4). Osmocote applied at 4.5 and $6.0 \mathrm{~g} \mathrm{~N} /$ pot had greater root zone $\mathrm{NO}_{3}-\mathrm{N}$ in May and June than at later months, and did not differ between July and Oct. 2015. Application at 7.5 and $9.0 \mathrm{~g} \mathrm{~N} /$ pot resulted in the greatest root zone $\mathrm{NO}_{3}-\mathrm{N}$ concentration in June 2015; the $\mathrm{NO}_{3}-\mathrm{N}$ concentration declined between June and Aug. 2015, and then remained relatively stable from Aug. to Oct. 2015. The $\mathrm{NH}_{3}-\mathrm{N}$ status in the root zone quadratically decreased for all CRF rates $>1.5 \mathrm{~g} \mathrm{~N} /$ pot between May and July 2015 but increased when CRF was applied at $9.0 \mathrm{~g}$ $\mathrm{N} /$ pot between July and Oct. 2015. The root zone $\mathrm{K}$ concentration decreased each month between May and Aug. 2015 for all CRF rates, except at $1.5 \mathrm{~g} \mathrm{~N} /$ pot, which declined between June and Sept. 2015. No significant change in root zone $\mathrm{P}$ was observed for any CRF rate applied between Aug. and Oct. 2015; however, at $7.5 \mathrm{~g} \mathrm{~N} /$ pot, the $\mathrm{P}$ concentration was greater in June and July than in Aug. 2015, and at $6.0 \mathrm{~g} \mathrm{~N} /$ pot, the $\mathrm{P}$ concentration was greatest in June 2015 (Fig. 4). When CRF was applied at $9.0 \mathrm{~g} \mathrm{~N} /$ pot, the $\mathrm{P}$ concentration was typically higher in Aug. and Sept. 2015 than for the other CRF rates used.

Substrate EC and $\mathrm{pH}$. Between May and Oct. 2015, substrate EC levels showed a cubic regression relationship with time for spirea and weigela grown with Plantacote at all CRF rates except $1.5 \mathrm{~g} \mathrm{~N} /$ pot, at all $\mathrm{CRF}$ rates except $3.0 \mathrm{~g} \mathrm{~N} /$ pot for spirea grown with Osmocote, and all rates except 1.5 and $3.0 \mathrm{~g}$ $\mathrm{N} /$ pot for weigela grown with Osmocote (Fig. 5). For spirea grown with both CRF types, at all rates except 1.5 and $3.0 \mathrm{~g} \mathrm{~N} /$ pot, the EC was greatest in June and reached the lowest levels toward the end of August for Osmocote, and in August and September for Plantacote. Similarly, for weigela grown with Osmocote at all rates except 1.5 and $3.0 \mathrm{~g} \mathrm{~N} /$ pot, the EC was highest in June and lowest in 


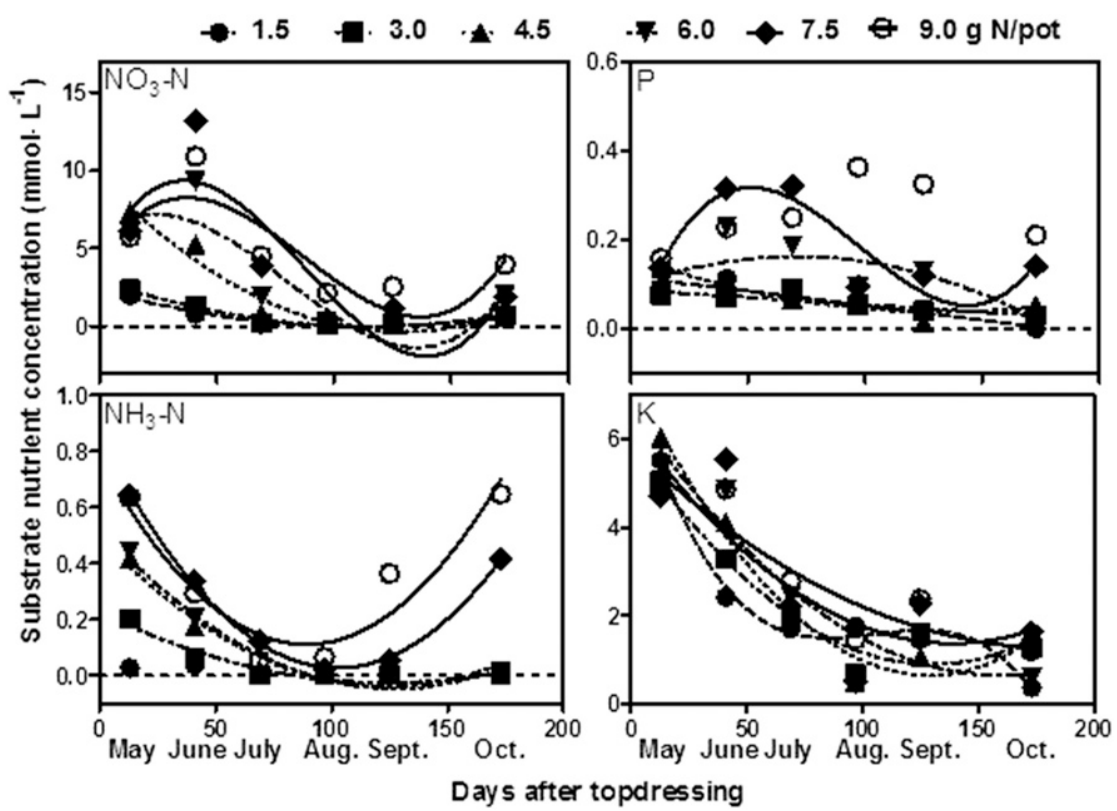

Fig. 4. Substrate nutrient concentration for 2-gal spirea topdressed on 7 May 2015 with Osmocote Plus $15 \mathrm{~N}-3.9 \mathrm{P}-9.9 \mathrm{~K}, 5-6$ month controlled-release fertilizer applied at six rates. Data are means of three replicates. Where effect of time was significant $(P<0.05)$, lines indicate the calculated regression, otherwise no lines are shown.

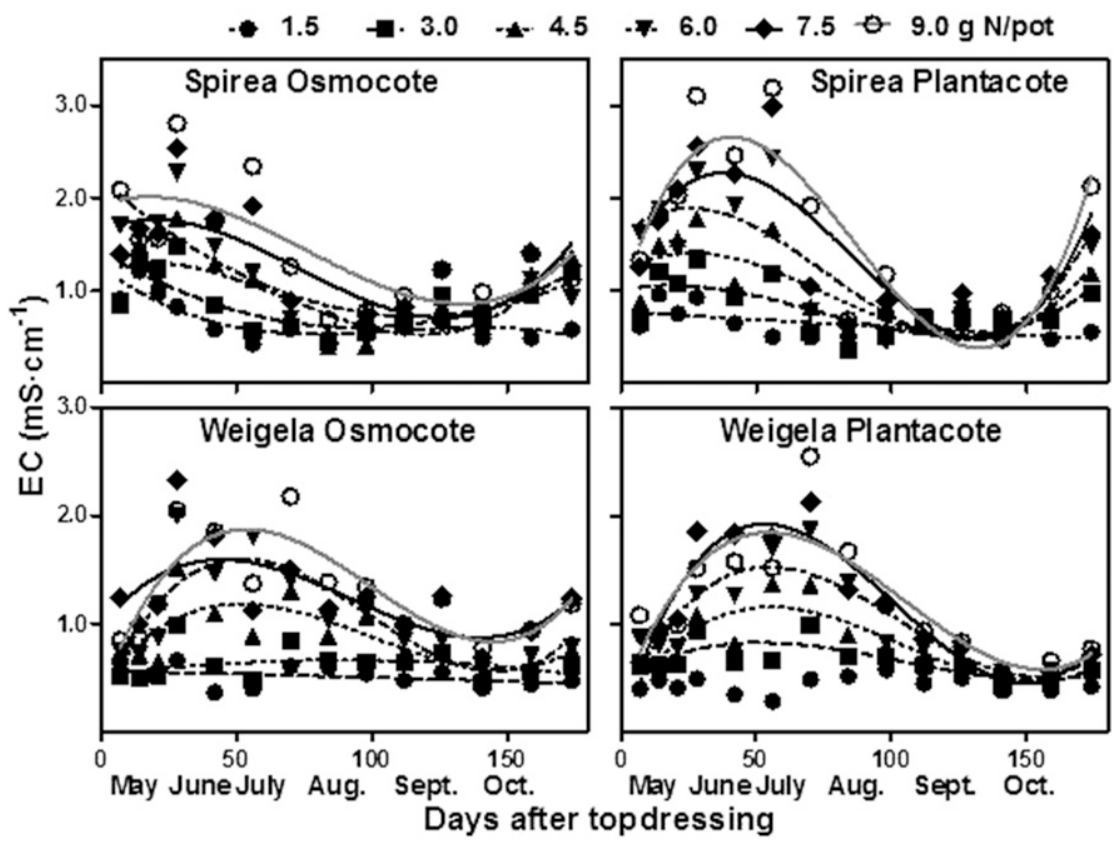

Fig. 5. Substrate EC for spirea and weigela topdressed on 7 May 2015 with Osmocote Plus $15 \mathrm{~N}-3.9 \mathrm{P}-$ 9.9K, 5-6 month or Plantacote 14N-3.9P-12.5K, 6 month Homogeneous NPK with Micros controlledrelease fertilizer, applied at six rates. Data are means five replicates. Where effect of time was significant $(P<0.05)$, lines indicate the calculated regression, otherwise no lines are shown.

Sept. 2015, while EC for weigela grown with Plantacote was highest in July at $4.5 \mathrm{~g} \mathrm{~N} /$ pot, and in June and July at $\geq 6.0 \mathrm{~g} \mathrm{~N} /$ pot; the EC was lowest in Sept. 2015 at $\geq 4.5 \mathrm{~g} \mathrm{~N} /$ pot. Interestingly, for most of the CRF rates applied (both CRF types) for both plant species, substrate EC values increased toward the end of the growing season. The EC from spirea fertilized with Osmocote was correlated with $\mathrm{NO}_{3}-\mathrm{N}$ at 1.5 and $9.0 \mathrm{~g} \mathrm{~N} /$ pot ( 0.91 and 0.83 , respectively), with $\mathrm{K}$ for
$1.5,6.0$, and $7.5 \mathrm{~g} \mathrm{~N} / \operatorname{pot}(0.89,0.82$, and 0.96 , respectively) and $\mathrm{NH}_{3}-\mathrm{N}$ for $6.0 \mathrm{~g} \mathrm{~N} /$ pot (0.81). However, the $\mathrm{P}$ concentrations at all CRF rates, and all nutrients at 3.0 and $4.5 \mathrm{~g} \mathrm{~N} /$ pot, were not correlated with the EC values.

Substrate $\mathrm{pH}$ was lower at high vs. low CRF rates for all species with both CRF types early in the 2015 growing season (Fig. 6). Specifically, compared with $1.5 \mathrm{~g} \mathrm{~N} /$ pot, the majority of $\mathrm{CRF}$ rates $\geq 6.0 \mathrm{~g} \mathrm{~N} /$ pot had lower substrate $\mathrm{pH}$ values from 3 June to 1
July 2015 for all species and CRF types. In addition, the $\mathrm{pH}$-reducing influence of $\mathrm{CRF}$ rate lasted until mid-July for both spirea with Plantacote and weigela with Osmocote at 9.0 g N/pot, whereas weigela with Plantacote at 7.5 and $9.0 \mathrm{~g} \mathrm{~N} /$ pot had lower $\mathrm{pH}$ levels than $1.5 \mathrm{~g} \mathrm{~N} /$ pot until 26 Aug. 2015. However, no $\mathrm{pH}$-influenced nutrient deficiency symptoms were observed during the study. Substrate $\mathrm{pH}$ from spirea fertilized with Osmocote was not correlated with the status of any nutrient for any CRF rate throughout the 2015 growing season.

Growing environment. The growing substrate volumetric water content ranged from 0.31 to $0.34,0.18$ to $0.46,0.10$ to 0.45 , and 0.09 to $0.42 \mathrm{~m}^{3} / \mathrm{m}^{3}$ for the seasonal month ranges of June to Sept. 2015, Sept. to Dec. 2015, Jan. to Mar. 2016, and Apr. to May 2016 , respectively. The temperature of the growing substrate ranged from 18.7 to 25.5 , 1.1 to $24.6,-0.3$ to 16.2 , and 0.3 to $30.3^{\circ} \mathrm{C}$ for the seasonal month ranges of June to Sept. 2015, Sept. to Dec. 2015, Jan. to Mar. 2016, and Apr. to May 2016, respectively. The surrounding air temperature ranged from 1.0 to $33.9,-9.7$ to $23.0,-17.4$ to 18.7 , and -6.4 to $33.4{ }^{\circ} \mathrm{C}$ for the seasonal month ranges of June to Sept. 2015, Sept. to Dec. 2015, Jan. to Mar. 2016, and Apr. to May 2016, respectively.

\section{Discussion}

For spirea topdressed with Osmocote, high $\mathrm{NO}_{3}-\mathrm{N}$ levels measured during spring and early summer at fertilizer treatment rates of $\geq 4.5 \mathrm{~g} \mathrm{~N} /$ pot indicated that Osmocote Plus $(15 \mathrm{~N}-3.9 \mathrm{P}-9.9 \mathrm{~K})$ rates of $\geq 4.5 \mathrm{~g} \mathrm{~N} /$ pot likely provided nutrients at levels above the requirements for spirea plants in this type of production system. However, $\mathrm{NO}_{3}-\mathrm{N}$ was either not detected or present at very low levels in the majority of the fertilizer treatments by Aug. 2015, indicating that by this time the amount of $\mathrm{NO}_{3}-\mathrm{N}$ released was either at, or lower than, levels required for optimal plant growth. Due to prevailing warm temperatures and availability of sufficient moisture, the majority of $\mathrm{NO}_{3}-\mathrm{N}$ may have already been released from the Osmocote prills by August (Broschat, 2005). Similarly, the concentration of $\mathrm{P}$ in the spirea growing substrate was high early in the season at Osmocote application levels of $\geq 6.0 \mathrm{~g} \mathrm{~N} /$ pot, and was probably greater than the amount required by the plants at that time of year. Growing substrate $\mathrm{NH}_{3}-\mathrm{N}$ concentrations were high at high Osmocote application rates in May 2015 and declined sharply thereafter, indicating over-fertilization relative to plant demand, early in the growing season. High $\mathrm{NH}_{3}-\mathrm{N}$ concentration was also detected at the end of the 2015 growing season at 7.5 and $9.0 \mathrm{~g} \mathrm{~N} /$ pot, which could indicate a reduced $\mathrm{NH}_{3}-\mathrm{N}$ uptake when the weather became colder. For some species, active nutrient uptake by plant roots can occur at or above $\approx 13{ }^{\circ} \mathrm{C}$ (Davenport and DeMoranville, 2004); thus, at temperatures below this threshold, nutrients may no longer 


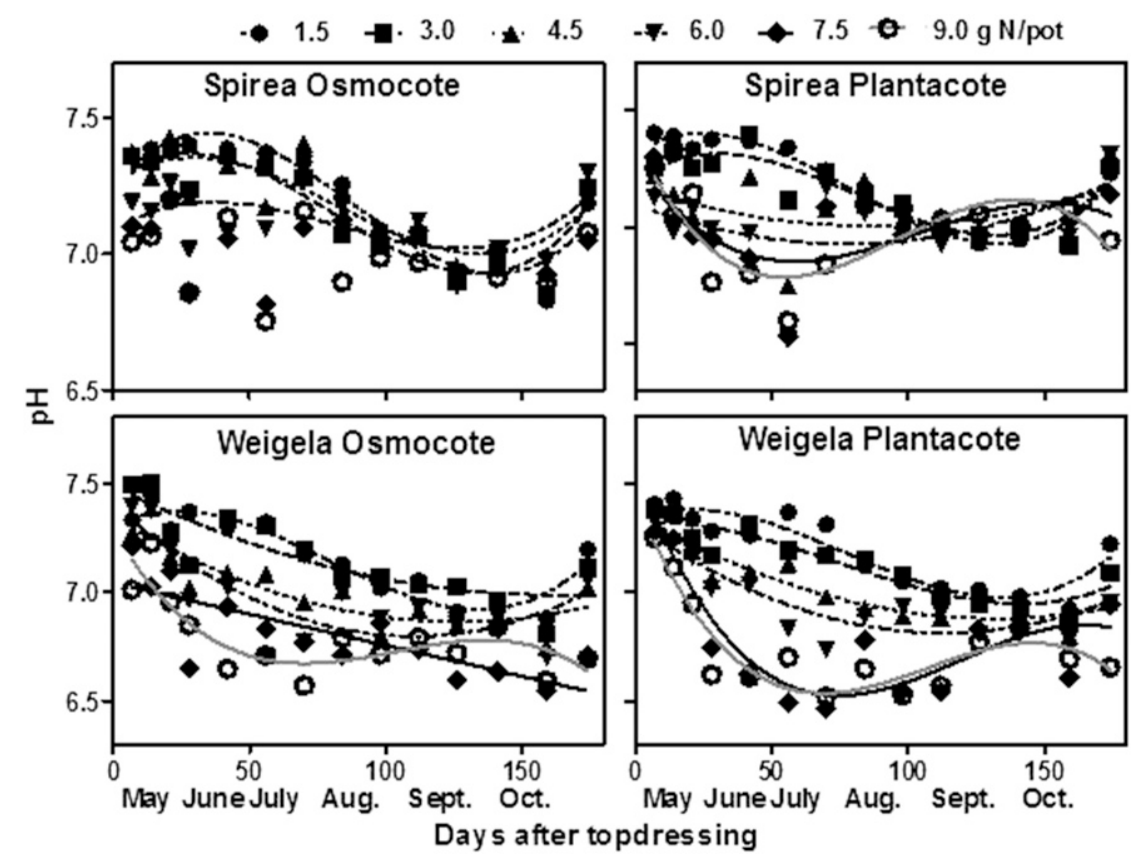

Fig. 6. Substrate $\mathrm{pH}$ for spirea and weigela topdressed on 7 May 2015 with Osmocote Plus $15 \mathrm{~N}-3.9 \mathrm{P}$ 9.9K, 5-6 month or Plantacote 14N-3.9P-12.5K, 6 month Homogeneous NPK with Micros controlledrelease fertilizer, applied at six rates. Data are means of five replicates. Where effect of time was significant $(P<0.05)$, lines indicate the calculated regression, otherwise no lines are shown.

be accessed by plant roots. If nutrients were continually released from the prills during cooler conditions and were not taken up by plants, this would lead to the observed increase in root zone nutrient levels late in the growing season. In addition, if microorganisms remained active at late-season low temperatures, nutrients may have been released through soil decomposition processes (Malhi and McGill, 1982). This relationship of temperature and growing substrate nutrient status may explain the slight increase in $\mathrm{NO}_{3}-\mathrm{N}, \mathrm{NH}_{3}-\mathrm{N}$, and $\mathrm{P}$ concentrations after Sept. 2015 at high CRF rates, since growing substrate temperatures ranged from 1.0 to $22.7,-3.0$ to $23.0,-2.8$ to 16.9 , and -9.7 to $9.6^{\circ} \mathrm{C}$ in Sept., Oct., Nov., and Dec. 2015. Since the lower range of these temperatures was below the temperature for nutrient uptake by plant roots, any released nutrients from CRF prills could have contributed to increased nutrient concentration in the growing substrate. Conversely, the concentration of $\mathrm{K}$ in the substrate was highest in May 2015 at all CRF rates and generally declined thereafter over the growing season. This pattern for $\mathrm{K}$ was also observed by Broschat (2005), who found that when CRFs were applied to the surface of a growing substrate, $\mathrm{K}$ levels rapidly declined (i.e., $<50 \%$ remaining after 5 months for an 8-9 month duration Osmocote $\mathrm{CRF}$ at $23{ }^{\circ} \mathrm{C}$ ). This may have been caused by a high uptake of $\mathrm{K}$ by plant roots early in the growing season, thereby depleting the $\mathrm{K}$ in the growing substrate, or by $\mathrm{K}$ leaching to the environment.

Hoskins et al. (2014) concluded that substrate EC measurements may also be used as indicators of $\mathrm{NO}_{3}-\mathrm{N}$ concentrations in the substrate, as it was the primary nutrient they observed in leachate from CRF-fertilized growing substrate in a container nursery production system. Our results build on this observation, and indicate that the concentrations of $\mathrm{NO}_{3}-\mathrm{N}, \mathrm{K}$, and $\mathrm{NH}_{3}-\mathrm{N}$ all correlated to substrate EC measurements for various CRF rate applications. Therefore, data from substrate EC measured from spirea with Plantacote and weigela with both CRF types could be used as an indicator of the status of these nutrients in the growing substrates for this system of container nursery production.

Nutrient status evaluations in the current study assisted in interpreting the observed nutrient deficiencies. Toward the end of the growing season, spirea at $1.5 \mathrm{~g} \mathrm{~N} /$ pot showed $\mathrm{N}$ deficiency symptoms, low root zone concentrations of $\mathrm{NO}_{3}-\mathrm{N}$ and $\mathrm{NH}_{3}-\mathrm{N}$, and low levels of root growth. These results confirm that a CRF application rate of $1.5 \mathrm{~g} \mathrm{~N} /$ pot was insufficient to ensure appropriate $\mathrm{N}$ was available to support healthy spirea growth through the growing season. Despite high substrate $\mathrm{pH}$ levels $(>6.5)$ observed throughout the study for the majority of CRF rates applied, the low $\mathrm{P}$ availability at such $\mathrm{pH}$ levels in growing substrates (Reed, 1996), and the low $\mathrm{P}$ concentrations observed at low CRF rates throughout the current study, no definitive $\mathrm{P}$ deficiency symptoms were observed. The absence of $\mathrm{P}$ deficiency symptoms may indicate the tolerance of these varieties of spirea and weigela to low P levels, or the leaf colors of the spirea (gold-colored) and weigela (wine-colored) cultivars may simply have masked visible $\mathrm{P}$ deficiencies. Although no P deficiencies were observed, weigela leaves clearly displayed $\mathrm{K}$ deficiency symptoms, which increased in severity over time; this corresponded to a decline in $\mathrm{K}$ levels measured in the root zone. These results present an opportunity for fertilizer companies to adjust specifications for the controlled-release coating material for $\mathrm{K}$ within a CRF prill, to ensure a longer release duration, prevent early-season $\mathrm{K}$ leaching and potentially reduce $\mathrm{K}$ deficiency symptoms for nursery crops. Despite the high substrate $\mathrm{pH}$ levels in the current study, no $\mathrm{pH}$-influenced nutrient deficiencies were observed during the growing season for these species. However, for nursery crops with greater $\mathrm{pH}$ sensitivities, the production practices in the current study may not prevent visible nutrient deficiencies. The high substrate $\mathrm{pH}$ observed in the current study, even though the CRF caused a reduction in $\mathrm{pH}$ early in the growing season, was likely due to the $\mathrm{pH}$ of the irrigation water, which ranged from 7.58 to 7.92 . Previous research with nursery crops in Ontario has demonstrated benefits of irrigation water acidification to prevent potential high-pH influenced nutrient deficiency symptoms (Zheng et al., 2013). For both spirea and weigela, and both CRF types, since root growth did not significantly differ between midrange and high $\mathrm{CRF}$ rate applications, plant roots in high CRF rate treatments did not appear to experience nutrient toxicity levels in the current study.

Optimum CRF application rates vary based on the production goals at individual nurseries. For example, some temperate climate nursery operations transplant shrubs into 2-gal containers in early spring with the goal of selling them a few months later, after the plants have established and grown to marketable size. Other nurseries have different production practices such as fall transplanting, different sales timelines, or multiple marketable sizes for finished nursery stock. In the production system used in the current study, shrubs were transplanted in the fall for sale by the end of the following year. Therefore, the optimum CRF rate at this nursery would ensure healthy plant growth through the growing season following transplanting, without excess growth or appearance of nutrient stress symptoms, and without nutrients leaching into the environment. Despite the perception that fast growth and large plants are desirable, timing of growth to match target production timelines is the more desirable goal. The current study identified CRF rates which met such goals during onsite evaluations in Sept. 2015. Although not the largest plants, the best plants selected by the evaluation team at the end of the growing season (23 Sept. 2015) were spirea grown with 3.0-4.5 and 3.0-6.0 g N/pot, and weigela grown with 3.0-4.5 and $6.0 \mathrm{~g} \mathrm{~N} /$ pot, for Osmocote and Plantacote, respectively. At these rates, the shrubs had reached marketable size at the Sept. 2015 time point during the production cycle, meeting nurserydetermined requirements. In addition, the majority of measured plant growth and quality characteristics did not significantly increase when higher CRF rates were used, and no winter injury was observed. However, the 
issue of $\mathrm{K}$ deficiency symptoms for all weigela, regardless of CRF application rate requires further research to determine the most appropriate solution in this production system.

Application of CRF within the selected range of 3.0-4.5 g N/pot resulted in low $P$ nutrient status, and would likely prevent negative environmental impacts which may occur at CRF application rates $>6.0 \mathrm{~g} \mathrm{~N} /$ pot. High levels of an early-season $\mathrm{NO}_{3}-\mathrm{N}$ nutrient status could be prevented by applying $\mathrm{CRF}$ at rates $<4.5 \mathrm{~g} \mathrm{~N} /$ pot. However, since CRF application at $6.0 \mathrm{~g} \mathrm{~N} /$ pot was the upper threshold for the optimal range for spirea grown with Plantacote and was the optimal rate for weigela grown with Plantacote, further research is needed to determine a production strategy to reduce high early-season substrate nutrient concentrations where there is greater potential for nutrient leaching, without compromising plant growth.

To apply the results of this current study to diverse production goals, Table 1 can be used to estimate target sales timelines to reach marketable size benchmarks, following an early-May CRF topdress application of Osmocote Plus $15 \mathrm{~N}-3.9 \mathrm{P}-9.9 \mathrm{~K}$ or Plantacote $14 \mathrm{~N}-3.9 \mathrm{P}-12.5 \mathrm{~K}$ to fall-transplanted spirea or weigela. For example, with the current production components, the fastest time for spirea to reach the $40-\mathrm{cm}$ marketable size would be $66 \mathrm{~d}$ after topdressing when fertilized with Osmocote at $7.5 \mathrm{~g} \mathrm{~N} /$ pot. For another production goal, e.g., to produce $30-\mathrm{cm}$ diameter weigela $>75 \mathrm{~d}$ after topdressing, application of $\leq 4.5 \mathrm{~g} \mathrm{~N} /$ pot would be appropriate.

Balancing CRF application rate with nursery crop production goals may provide an opportunity to reduce nutrient leaching and prevent negative environmental impacts. In addition, the observed high nutrient concentrations of the growing substrate early in the growing season following falltransplanting can be mitigated by applying topdressed CRF at rates $<4.5$ to $6.0 \mathrm{~g} \mathrm{~N} /$ pot.

\section{Literature Cited}

Agro, E.E. 2014. Optimum controlled release fertilizer rates for containerized nursery plant production in Ontario. Univ. of Guelph, Guelph, MSc. Diss.
Agro, E.E. and Y. Zheng. 2014. Controlled-release fertilizer application rates for container nursery crop production in southwestern Ontario, Canada. HortScience 49:1414-1423.

Alam, M.Z., C. Chong, J. Llewellyn, and G.P. Lumis. 2009. Evaluating fertilization and water practices to minimize $\mathrm{NO}_{3}-\mathrm{N}$ leachate from containergrown Forsythia. HortScience 44:1833-1837.

Birrenkott, B.A., J.L. Craig, and G.R. McVey. 2005. A leach collection system to track the release of nitrogen from controlled-release fertilizers in container ornamentals. HortScience 40:1887-1891.

Broschat, T.K. 2005. Rates of ammoniumnitrogen, nitrate-nitrogen, phosphorus, and potassium from two controlled-release fertilizers under different substrate environments. HortTechnology 15:332-335.

Cabrera, R. 1997. Comparative evaluation of nitrogen release patterns from controlled-release fertilizers by nitrogen leaching analysis. HortScience 32:669-673.

Chen, Y., R.P. Bracy, A.D. Owings, and J.P Quebedeaux. 2011. Controlled-release fertilizer type and rate affect landscape establishment of seven herbaceous perennials. HortTechnology 21:336-342.

Clark, M.J. and Y. Zheng. 2015. Species-specific fertilization can benefit container nursery crop production. Can. J. Plant Sci. 95:251-262.

Davenport, J.R. and C. DeMoranville. 2004. Temperature influences nitrogen release rates in cranberry soils. HortScience 39:80-83.

Environment Canada. 2016. Climate: Daily data (2015, 2016). 7 July 2016. <http://climate.weather.gc.ca/ climate_data/daily_data_e.html?hlyRange $=2002$ $02-15 \% 7 \mathrm{C} 2016-07-06 \&$ dlyRange $=2002-02-07 \%$ 7C2016-07-05\& mlyRange $=2003-10-01 \%$ 7C2006-12-01\&StationID=31367\&Prov $=$ ON\& urlExtension=_e.html\&searchType $=$ stnProx\& optLimit $=$ specDate $\&$ Month $=5 \&$ Day $=1 \&$ Star tYear $=2016 \&$ End $Y$ ear $=2016 \&$ Year $=2016 \&$ selRowPerPage $=25 \&$ Line $=2 \&$ txtRadius $=$ 25\&optProxType $=$ navLink\& txtLatDecDeg= 43.191666666667\&txtLongDecDeg=79.17111 1111111 \& timeframe $=2>$.

Hershey, D.R. and J.L. Paul. 1982. Leaching-losses of nitrogen from pot chrysanthemums with controlled-release or liquid fertilization. Sci. Hort. 17:145-152.

Hoskins, T.C., J.S. Owen, Jr., and A.X. Niemiera. 2014. Controlled-release fertilizer placement affects the leaching pattern of nutrients from nursery containers during irrigation. HortScience 49:1341-1345.

Husby, C.E. 2000. Influence of temperature and time on nutrient release patterns of Osmocote
Plus $^{\mathrm{TM}}$, Nutricote ${ }^{\mathrm{TM}}$, and Polyon ${ }^{\mathrm{TM}}$ controlledrelease fertilizers. Virginia Polytech. Institute and State Univ. Blacksburg, MSc. Diss.

Majsztrik, J.C., A.G. Ristvey, and J.D. Lea-Cox. 2011. Water and nutrient management in the production of container-grown ornamentals. Hort. Rev. 38:253-296.

Malhi, S.S. and W.B. McGill. 1982. Nitrification in three Alberta soils: Effect of temperature, moisture and substrate concentration. Soil Biol. Biochem. 14:393-399.

Narvaez, L., R. Caceres, and O. Marfa. 2012. Effects of climate and fertilization strategy on nitrogen balance in an outdoor potted crop of Viburnum tinus L. Span. J. Agr. Res. 10:471481.

Newman, J.P., J.P. Albano, D.J. Merhaut, and E.K. Blythe. 2006. Nutrient release from controlledrelease fertilizers in a neutral-pH substrate in an outdoor environment: I. Leachate electrical conductivity, $\mathrm{pH}$, and nitrogen, phosphorus, and potassium concentrations. HortScience 41:1674-1682.

Lunt, O.R. and J.J. Oertli. 1962. Controlled release of fertilizer minerals by incapsulating membranes: II. Efficiency of recovery, influence of soil moisture, mode of application, and other considerations related to use. Soil Sci. Soc. Proc. 26:584-587.

Reed, D.W. 1996. A grower's guide to water, media, and nutrition for greenhouse crops. Ball Publishing, Batavia, IL

Ruter, J.M. 1992. Influence of source, rate, and method of applying controlled release fertilizer on nutrient release and growth of 'Savannah' holly. Fert. Res. 32:101-106.

Wright, R.D. 1986. The pour through nutrient extraction procedure. HortScience 21:227229.

Yeager, T. and G. Cashion. 1993. Controlledrelease fertilizers affect nitrate nitrogen runoff from container plants. HortTechnology 3:174177.

Yeager, T., R. Wright, D. Fare, C. Gilliam, J. Johnson, T. Bilderback, and R. Zondag. 1993. Six state survey of container nursery nitrate nitrogen runoff. J. Environ. Hort. 11:206-208.

Zanin, G., P. Sambo, and G. Ponchia. 2011. Production of containerized boxwood with different substrates and fertilizer rates. Acta Hort. 927:1021-1028.

Zheng, Y., M.J. Clark, E. Agro, and K. Vinson. 2013. Fertilizer can be used as a management tool in container nursery production. 7 July 2016 . <https://www.vinelandresearch. com/sites/default/files/2013 nursery_fertilizer report.pdf $>$. 